\title{
Application of digital platforms in the urban infrastructure development
}

\author{
Timur Ablyazov* \\ Saint Petersburg State University of Architecture and Civil Engineering, 4 Vtoraya \\ Krasnoarmeiskaya, 190005, Saint Petersburg, Russian Federation
}

\begin{abstract}
In the context of the digital economy, one of the main directions for the development of the human environment is the digital transformation of cities. Digital platforms in the field of urban infrastructure are a key instrument for digitalizing territories. The paper substantiates that the transformation of urban infrastructure is an important trend in the development of territories, and also describes the benefits that can be obtained through the introduction of digital technologies into the human environment. As a result of the study, the issues of integration of physical and digital infrastructure of cities were assessed and it was concluded that the functioning of digital platforms is based on the establishment of interconnections between infrastructure objects and data storages through information and communication technologies. The prospects of introducing the Internet of Things into the urban infrastructure as a way to improve the process of interaction of all elements of the human life environment during the implementation of digital platforms are also considered.
\end{abstract}

\section{Introduction}

According to UN estimates, by 2050 the world's population will reach 9.7 billion people, which is 2 billion more than the current level [1]. Moreover, an increase in the share of the urban population is projected, which will undoubtedly lead to an increase in the load on urban infrastructure, which is not designed for such a high population and density of residence. One of the perspective directions of improvement of territories is the implementation of digital technologies in all aspects of the activity of the city that in total will lead to the transformation of the environment of human life. In our opinion, the development of the practice of the use of digital platforms as instruments of improvement of the environment of life is a key element of the process of digitalization of the cities.

\footnotetext{
${ }^{*}$ Corresponding author: $\underline{3234969 @ \text { mail.ru }}$
} 


\section{Materials and methods}

Currently, as a result of the fourth industrial revolution, there is a spread of such most modern technologies as the Internet of Things, cloud storage and data processing systems, blockchain [2], unmanned vehicles, augmented and virtual reality, etc. [3]. Moreover, a further reduction in the need for routine work previously performed by people will be based on artificial intelligence and machine learning, which will not only speed up the process of producing goods and providing services, but will also become the basis for making informed decisions in the field of territory management [4].

Cisco foresees that the potential benefits from digital transformation of cities by 2024 could amount to USD 2.3 trillion, with $48 \%$ coming from the formation of a qualitatively new labor market and the improvement of processes related to the functioning of organizations [5]. Urban services account for $18 \%$ of the total potential benefits, security $11 \%$, transport systems $-8 \%$, comfort of life in cities $-6 \%$, urban development management $-3 \%$, the formation of open data $-2 \%[5]$.

It is already recognized today that the digital transformation of cities is based on the interdisciplinary interaction of specialists in the field of architecture, urban planning, construction, transport, information and communication technologies, utilities, sociology, public finance, ecology, political science, advertising [6]. Such cooperation allows to develop the digital systems comprising the digital platforms (ecosystems) based on processing of a set of operations, data, inquiries of users, estimates of the rendered services, etc. integrated among themselves. Despite the absence in the scientific community of a unified approach to the definition of a smart (or digital) city [7, 8], in general, this concept includes the development of the living environment in such areas as territorial management, technology, economy, environment, infrastructure (transport, energy, utilization of household waste, housing and communal services), health care, education, safety [9]. The integration of these areas within digital platforms and, as a result, the aggregation of data on the functioning of the territory and their analysis will allow, based on the adoption of qualitatively new decisions, to reduce the number of crimes by $30-40 \%$, save $30-300$ more people per year (by 5 million population), to achieve 15-30 minutes of saving time for moving around the city, to reduce the volume of water consumption per person per day by 25-80 liters, to increase the response speed of emergency services by $20-35 \%$ [10].

\section{Results}

The main trends in the development of urban areas in the context of the digitalization of the human life environment are increasing the mobility of the population through the introduction of intelligent transport systems, the formation of big data on the functioning of the city, the ubiquity of gadgets and the Internet, as well as the development of digital services that can meet all the requirements of modern society [11]. As a result of the use of digital technologies, it becomes possible for the emergence of such areas of urban development as smart factories, smart homes, distributed consumption, energy-saving practices, e-commerce, digital calculations, as well as the prevention of situations that negatively affect the safety and comfort of the living environment [12].

One of the difficulties accompanying the process of city transformation on the way to the formation of digital platforms is the impossibility of integrating digital and physical infrastructure into a single system. Nevertheless, digital platforms cannot exist in isolation from the existing infrastructure of the territory, since they are designed to simplify the interaction of residents, organizations, and authorities, and not replace the existing life processes of the city. The smart city infrastructure can be divided into physical (hard) and non-physical (soft), which cannot function efficiently without integration with each other 
(Fig. 1). While the physical infrastructure performs the functions of transmitting and storing data, the non-physical (or digital) is responsible for processing information through various services, applications, terminals, and devices.

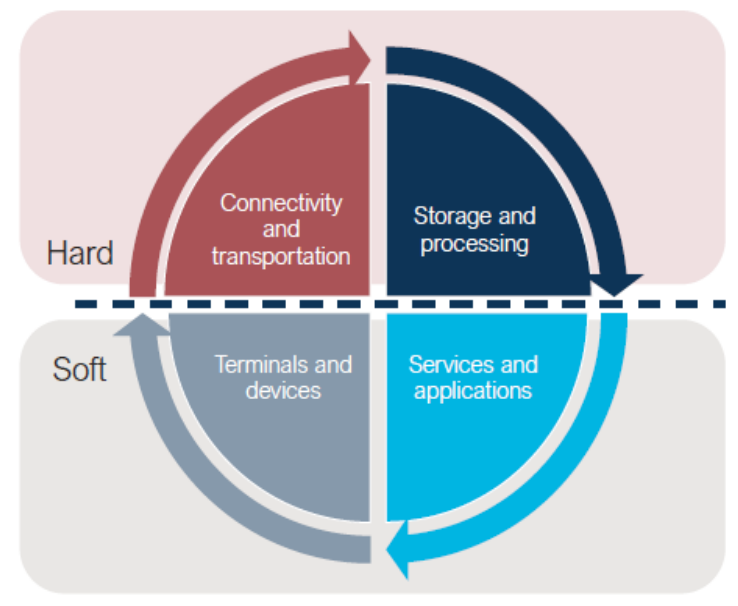

Fig. 1. The process of functioning of the infrastructure of a smart city [11].

We can say that the digital platform is the central link of the smart city, through which the interaction of various services and applications used by the population with the infrastructure of the territory is carried out [13]. Moreover, the exchange of data is two-way, since, on the one hand, information enters the digital platform, and on the other hand, the big data stored on the platform serves as the basis for improving the physical infrastructure. Thus, the process of circulation of information within the territory can be characterized as continuous data flows between physical and digital infrastructures.

Accordingly, the key trend in the development of the living environment in the digital economy is to ensure efficient, fast, uninterrupted, and safe interaction of the territory's infrastructures with a single digital platform or its individual systems that correspond to the specifics of a particular sphere of life. It is recognized that in order to collect information about the city in real time, it is necessary to form sensor networks based on the use of available mobile devices [14], introduce radio frequency identification (RFID) technologies, photo and video cameras [15]. As a result, the data goes to processing centers capable of analyzing such huge amounts of information [16], which is further used to improve the data collection process and develop new technologies. Thus, the formation of digital platforms is based on the transformation of the physical infrastructure of territories, which requires the simultaneous introduction of digital technologies in all areas of digitalization of cities.

\section{Discussion}

The Internet of Things is the most perspective technology allowing to integrate the physical and digital infrastructures of the urban environment into the digital platform. This technology is based on combining disparate elements (devices) into a single interaction environment in order to achieve common goals $[17,18]$. It is important that the connection to the Internet of Things network should be available from all devices, as well as the opposite - the use of each device should allow to connect to the interaction network [13].

The Internet of Things can be used in the field of traffic regulation, monitoring of utility networks, urban lighting, management of the waste collection and disposal system, environmental control, and public safety [19]. 
At present, the attention of the scientific community is paid to the issues of standardizing the interaction of devices of the Internet of Things with each other, organizing its structure, but the large-scale implementation of this technology in the entire urban infrastructure is still a difficult and unsolved problem [20]. Organization of the Internet of Things network in a smart city requires the fulfillment of the following conditions [21]:

- Ensuring consistency between heterogeneous IoT devices through standardization.

- Data collection needs to be done in real time, and data warehouses need to be able to receive this amount of information.

- The flexibility of the Internet of Things network can be achieved by introducing separate microservices for each process [22], which will allow maintaining the stability of the network both in the event of failure of individual network elements and in general in an unstable external environment with constantly changing conditions.

- Raising the awareness of device users about the conditions for collecting and transferring data, as well as developing the practice of analyzing user experience in order to improve the services offered.

\section{Conclusion}

Thus, the introduction of digital platforms in the field of urban infrastructure transformation is one of the most promising areas for the development of the human environment in the digital economy. The key problem of digitalization of territories is the complexity of the process of integrating physical and digital urban infrastructure. In our opinion, overcoming this barrier to the digital transformation of the living environment is possible through the use of the Internet of Things technology, since it is precisely as a result of the complex integration of all elements of the urban infrastructure that it becomes possible to form a digital platform that acts as the central link in the functioning of the territory in the digital economy.

The article was written as part of the work on the Grant of the President of the Russian Federation MK462.2020.6.

\section{References}

1. United Nations, E/CN.9/2020/5 (2020)

2. T. Ablyazov, I. Petrov, Materials Science and Engineering 497 (2019).

3. K. Schwab, The Fourth Industrial Revolution (World Economic Forum: Geneva, Switzerland, 2016)

4. H. Schaffers, N. Komninos, M. Pallot, B. Trousse, M. Nilsson, A.Oliveira, Future Internet Assembly (Budapest, Hungary, 2011)

5. J. Barbier, K. Delaney, N. France, Cisco (2017)

6. C. Harrison, I. A. Donnelly, Annual Meeting of the International Society for the Systems Sciences (Hull, UK, 2011)

7. A. Cocchia, Smart City (Springer, Cham., 2014)

8. A. Vishnivetskaya, E. Alexandrova, Materials Science and Engineering 497 (2019)

9. H. Chourabi, T. Nam, S. Walker, R. Gil-Garcia, S. Mellouli, K. Nahon, T. Pardo, H. Jochen, S. Chourabi, International Conference on System Sciences (Maui, HI, USA, 2012)

10. McKinsey, Smart cities: digital solutions for a more livable future (McKinsey \& Company, 2018) 
11. Asian Infrastructure Investment Bank, Digital Infrastructure Sector Analysis (2020)

12. A. Booth, N. Mohr, P. Peters, The digital utility: New opportunities and challenges (McKinsey \& Company, 2016)

13. L. Sánchez, I. Elicegui, J. Cuesta, L. Muñoz, J. Lanza, Sensors-Basel 13, 14438 (2013)

14. G. Bell, T. Hey, A. Szalay, Science 323, 1297 (2009)

15. D. M. Gann, M. Dodgson, D. Bhardwaj, IBM J. Res. Dev. 55 (2011)

16. S. Palmisano, Welcome to the Decade of Smart (London, U.K, Chatham House, 2010)

17. I. Toma, E. Simperl, G. Hench, STI Roadmapping Workshop (Crete, Greece, 2009)

18. L. Atzori, A. Iera, G. Morabito, Comput. Netw. 54, 2787 (2010)

19. A. Grizhnevich, IoT for Smart Cities: Use Cases and Implementation Strategies (2021)

20. T. K. Ablyazov, International Business Information Management Association Conference, 6107 (2019)

21. E. Patti, A. Acquaviva, IEEE International Forum on Research and Technologies for Society and Industry Leveraging a better tomorrow (Bologna, Italy, 2016)

22. S. Newman, Building Microservices (O’Reilly Media, 2015) 